\title{
Miyaz İçin Risk Faktörü Bulundurmayan Bir Kadın Hastada Psychoda spp. Kaynaklı Ürogenital Miyaz Olgusu
}

\section{Urogenital Myiasis Caused by Psychoda spp. in Female Patient with No Risk Factor for Myiasis}

\author{
Fatma ESENKAYA TAŞBENT¹ (ID), Bilal DiK²(ID), Esma KEPENEK KURT ${ }^{3}$ (ID) \\ ${ }^{1}$ Necmettin Erbakan Üniversitesi Meram Tıp Fakültesi, Tıbbi Mikrobiyoloji Anabilim Dalı, Konya. \\ ${ }^{1}$ Necmettin Erbakan University Meram Faculty of Medicine, Department of Medical Microbiology, Konya, Turkey. \\ 2 Selçuk Üniversitesi Veteriner Fakültesi, Parazitoloji Anabilim Dalı, Konya. \\ 2 Selcuk University Faculty of Veterinary, Department of Parasitology, Konya, Turkey. \\ ${ }^{3}$ Necmettin Erbakan Üniversitesi Meram Tıp Fakültesi, Enfeksiyon Hastalıkları ve Klinik Mikrobiyoloji Anabilim Dalı, \\ Konya. \\ ${ }^{3}$ Necmettin Erbakan University Meram Faculty of Medicine, Department of Infectious Diseases and Clinical Microbiology, \\ Konya, Turkey.
}

Makale Atıfı: Esenkaya Taşbent F, Dik B, Kepenek Kurt E. Miyaz için risk faktörü bulundurmayan bir kadın hastada Psychoda spp. kaynaklı ürogenital miyaz olgusu. Mikrobiyol Bul 2020;54(3):490-496.

\section{öz}

Miyaz, bazı sineklerin yumurta ve larvalarını insan veya hayvanların canlı organ ve dokularına ya da burun, göz, kulak vb. boşluklarına bırakması, larvaların orada gelişmeleri ve patolojik bozukluklara neden olması olarak tanımlanmaktadır. Seyrek görülen miyaz türlerinden biri de ürogenital miyazdır. Bu durum, ürogenital bölgenin hemen hemen tüm toplumlarda giysilerle kapatılması ve dolayısılla sineklerin bu bölgeye ulaşma ve yumurtalarını bırakma şanslarının daha az olmasıyla ilişkilendirilmektedir. Miyazda düşük sosyokültürel düzey ve kötü hijyen koşulları en önemli risk faktörleri olarak belirlenmiştir. Diğer yandan insan yaşam alanları içinde tuvaletler; barındırdıkları nem ve mikrobiyal ortam dolayısıyla, bakterilerle beslenen sinek larvaları için ideal ortamlardır. Özellikle altta yatan enfeksiyon varlığında oluşan kötü koku nedeniyle sineklerin bu bölgeye yumurta ya da larvalarını bırakmak için daha istekli oldukları belirtilmektedir. Bu olguda altta yatan kronik hastalığı olmayan, genital bölgede açık yara bulunmayan, üriner enfeksiyon tespit edilmeyen, yükseğe yakın orta sosyokültürel düzeyde bir hastaya ait ürogenital miyaz olgusu sunulmuştur. Konya şehir merkezinde bir apartman dairesinde ailesi ile birlikte ikamet eden 53 yaşındaki kadın hasta, idrarında hareket eden kurtçuklar görme şikayeti ile enfeksiyon hastalıkları polikliniğine başvurmuştur. Hasta yaklaşık 2 haftadır idrar yaparken kurtçuklar gördüğünü; hareketli kurtçukların kendi idrarından geldiğinden emin olmak için, idrarını bir toplama kabına aldığını ve orada da kurtçukları görmesi üzerine hastaneye başvurduğunu belirtmektedir. Hastadan alınan larvalar Psychoda spp.'ye ait 4. evre larva olarak tanımlanmışır. İdrarında hafif yanma dışında klinik şikayeti bulunmayan hastada, genitoüriner bölgede açık lezyon ya da yara izlenmemiştir. Hastanın tam kan sayımı normal olup idrar kültüründe üreme olmamıştır. Birlikte yaşadığı diğer aile bireylerinde benzer şikayet olmadığı

Iletişim (Correspondence): Dr. Öğr. Üyesi Fatma Esenkaya Taşbent, Necmettin Erbakan Üniversitesi Meram Tıp Fakültesi, Tıbbi Mikrobiyoloji Anabilim Dalı, 42090 Meram, Konya, Türkiye. Tel (Phone): +90 332221 0500, E-posta (E-mail): fesentas@hotmail.com 
belirtilmiştir. Psychoda spp.'ye bağlı genitoüriner miyaz tanısı konulan hastaya, hijyen ve hastalık ilişkisi ile ilgili bilgi verilmiş, tedavi olarak da üriner antiseptik başlanmıştır. Tedavi sonrası takiplerinde hastanın idrarında larva görülmemiştir. Sonuç olarak, ülkemizdeki birçok bölge iklim şartları açısından Psychoda cinsi erişkin sineklerin yaşaması için uygundur. Ürogenital miyaz açısından daha az risk faktörü olan hastalarda da enfestasyon gelişebileceği, ancak tedavi ve takip yapılmayan olgularda larvaların sayıca artabileceği, enfestasyonun kronikleşip daha ciddi klinik bulguların gelişebileceği düşünülmektedir. Bu tür olgularda hem gerekli tedavi ve takip yapılmalı hem de hastaya enfestasyonla hijyen arasındaki ilişkiye dikkati çeken bir eğitim verilmelidir.

Anahtar kelimeler: Psychodidae; ürogenital miyaz; diptera; Türkiye

\section{ABSTRACT}

Myiasis is defined as follows; some flies lay their eggs and larvae on live organs and tissues or on cavities of nose, eye, ear and etc of humans or animals and the larvae develop there and cause pathological disorders. One of the rare types of myiasis is the urogenital myiasis. This condition has been associated with covering urogenital area with clothes in almost all populations and therefore, less chance for flies to reach this site and lay their eggs. Low socio-cultural level and poor hygiene conditions are stated as the most important risk factors of myiasis. On the other hand, toilets within the human living spaces are ideal environments for fly larvae that are fed on bacteria as they contain moisture and a microbial environment. It is stated that especially in case of the presence of an underlying infection, flies are more prone to lay their eggs or larvae on this area due to the bad smell. In this case report, a patient with a moderate sociocultural level with no underlying chronic disease, no open wound in the genital area and no urinary tract infection was presented. A 53-year-old female patient living with her family in an apartment flat in the city center of Konya admitted to the outpatient clinic of infectious diseases with the complaint of moving worms in her urine. The patient stated that she had seen maggots while urinating for two weeks and that she passed her urine into a container to be sure that the maggots were coming from her urine, upon seeing the maggots there she has admitted to the hospital. The Larvae were defined as the fourth stage larvae of Psychoda spp. No open lesions or wounds were seen in genitourinary area of the patient who had no complaints other than mild urinary burning. Complete blood count test results of the patient were normal and there was no growth in her urine culture. It was stated that other family members whom she lived with did not have similar complaints. The patient was diagnosed as genitourinary myiasis caused byPsychoda spp. and informed about the relationship between hygiene and the disease. And urinary antiseptics were initiated as the treatment for the patient. After the treatment, no larvae were seen in the urine of the patient. In conclusion, many regions are suitable for Psychoda type of adult flies to live in our country due to the climate conditions. It is considered that infestation may develop in patients with less risk factors in terms of urogenital myiasis, that larvae may increase in number of patients who are not treated or followed up and that the infestation may become chronic and results in more serious clinical conditions. The necessary treatment and follow-up must be performed in such cases and the patients should be educated about the relationship between infestation and hygiene.

Keywords: Psychodidae; urogenital myiasis; diptera; Turkey

\section{Giriş}

İlk kez 1840'lı yıllarda kullanılmış olan miyaz terimi, bazı sinek yumurta ve larvalarının canlı dokulara ya da boşluklara bırakılması olarak bilinmektedir ${ }^{1,2}$. Sinek larvalarının oluşturduğu klinik bulgular, sinek türüne ve yerleştiği bölgeye göre değişmektedir. Klinik semptomsuz bir seyir gösterebildiği gibi, larvaların vücut boşluklarında ilerlemesi, hayati dokulara zarar vermesi ve sekonder enfeksiyonlara zemin hazırlaması nedeniyle ciddi hastalık nedeni olabilmektedir ${ }^{3,4}$. 
Ürogenital miyaz, miyazın en az sıklıkta görülen türüdür. Kötü hijyen koşulları, düşük sosyokültürel düzey, kişide diyabet gibi kronik hastalık varlığı, üretral kateter, üriner enfeksiyon, üriner obstrüksiyon, genital bölgede ülsere lezyon ya da enfeksiyon olması başıca risk faktörleridir. Ayrıca hayvancılıkla uğraşılan bölgelerde, kırsal alanlarda miyaz sinekleri daha sıklıkla görülmektedir ${ }^{5,6}$.

Ürogenital miyazda çok sayıda etken bildirilmektedir. Bunlardan Psychoda spp.'ye ait olgu bildirimleri literatürde sıklıkla Türkiye'den yapılmışıı ${ }^{3,7}$. Psychoda sinekleri genellikle nemli yerlerde, özellikle banyo ve tuvaletlerde, mutfaklarda, kanalizasyon drenajlarının ve sıhhi tesisat armatürlerinin bulunduğu yerlerde görülür. $1 \mathrm{~cm}$ 'den daha küçük boyutlarda, koyu renkli, uçuşan güve benzeri böceklerdir ${ }^{3,7,8}$.

Bu raporda, Konya şehir merkezinde yaşayan, idrarında hareketli kurţ̧uklar görme şikayetiyle başvuran bir hastaya ait ürogenital miyaz olgusu sunulmuştur.

\section{OLGU SUNUMU}

Bu çalışma, Necmettin Erbakan Üniversitesi Meram Tıp Fakültesi ilaç ve Tıbbi Cihaz Dışı Araştırmalar Etik Kurul onayı ile gerçekleştirildi (Tarih: 07.02.2020 ve Karar no: 2020/2314) ve hastadan yazılı onam alındı.

Konya şehir merkezinde bir apartman dairesinde ailesi ile birlikte ikamet eden 53 yaşındaki kadın hasta, idrarında hareket eden kurtçuklar görme şikayetiyle enfeksiyon hastalıkları polikliniğine başvurmuştur. Hastanın yanında getirmiş olduğu yaklaşık $1 \mathrm{~cm}$ boyutundaki kurtçuklar, önce Necmettin Erbakan Üniversitesi Meram Tıp Fakültesi Mikrobiyoloji Laboratuvarına, daha sonra da Selçuk Üniversitesi Veteriner Fakültesi Parazitoloji Laboratuvarına gönderilmiştir. Teşhis anahtarı kullanılarak her iki laboratuvarda da incelenen larvaların 4. dönem Psychoda spp. larvası oldukları belirlenmiştir (Resim 1-4) ${ }^{9}$. Psychoda cinsi içinde $250^{\prime}$ den fazla tür olduğu belirtilmektedir ${ }^{8}$. Her ne kadar literatürdeki birçok çalışmada ${ }^{9-11}$ Palearktik Bölgede (Türkiye'nin ve Orta Doğu'nun da içinde bulunduğu

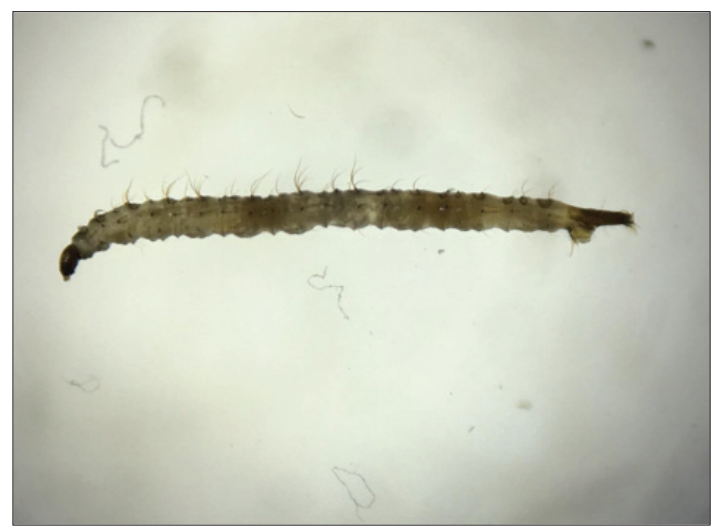

Resim 1. Idrardan alınan dördüncü dönem Psychoda spp. larvası, orijinal. 


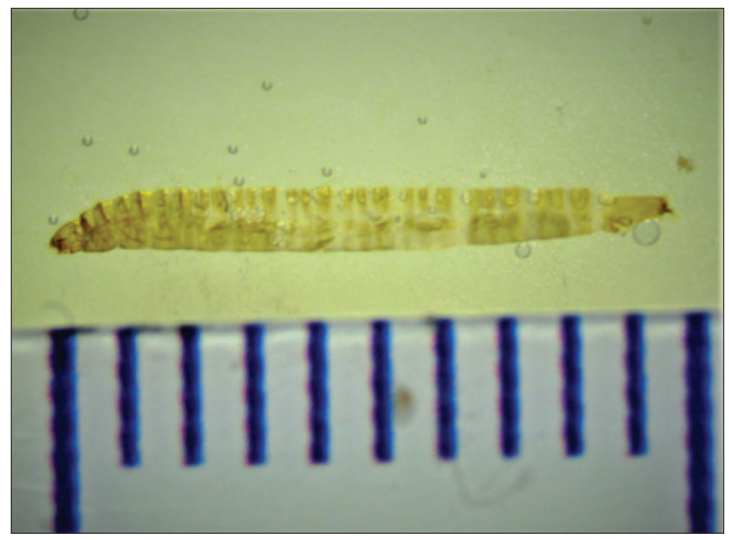

Resim 2. Psychoda spp., L4, saydamlaştırılmış, orijinal.

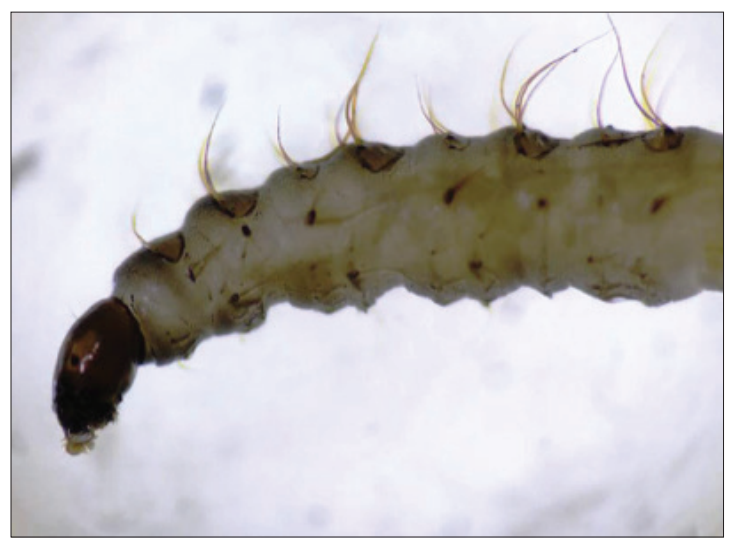

Resim 3. Dördüncü dönem Psychoda spp. larvası, anterior uç, orijinal.

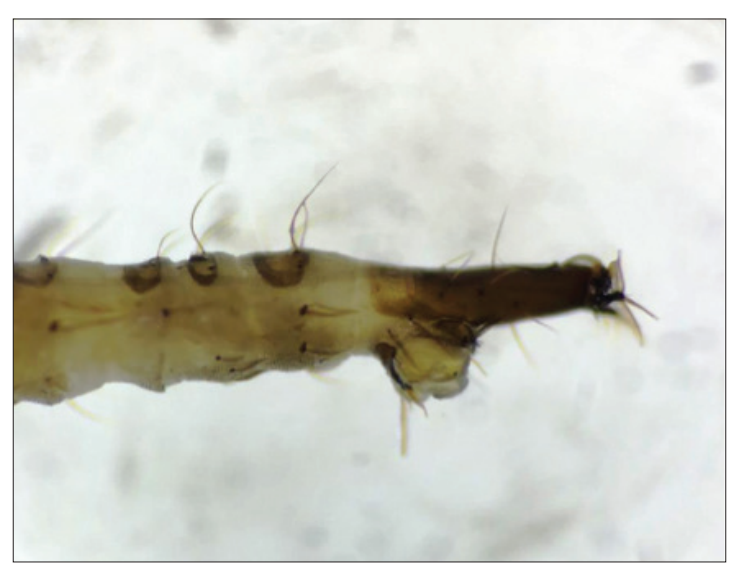

Resim 4. Psychoda spp., L4, posterior uç, orijinal. 
Avrupa'yı içine alan coğrafik bölge) ürogenital miyaza neden olan tek türün Psychoda albipennis olduğu bildirilse de, tüm türler arasında net ayrım yapılamamasından dolayı, bilimsel bir hata olmaması için tanımlama Psychoda spp. olarak yapılmıştır. Mikroskobik inceleme sırasında saydamlaştırma yapılmıştır. Bunun için \%70'lik alkol içinde saklanan larvalar, \%10'luk potasyum hidroksit içinde, saydamlaşıncaya kadar birkaç gün bekletilmiştir. Daha sonra distile suda birkaç saat bekletilip, \%70'lik ve \%99'luk alkol serilerinden geçirilmiş ve Kanada balsamı ile lam üzerine yapıştırılmıştır. $50^{\circ} \mathrm{C}$ etüvde $2-3$ hafta kurumaya bırakılan lamlar mikroskop incelemesi için hazır hale getirilmiştir.

Alınan detaylı anamnezde, hasta yaklaşık iki haftadır idrar yaparken kurtçuklar gördüğünü ve bu durumun tuvaletten kaynaklanabileceğini düşünerek evdeki dezenfektanlarla tuvaleti temizlediğini, fakat daha sonra da kurtçukları görmeye devam ettiğini belirtmiştir. Hasta, hareketli kurtçukların kendi idrarından gelip gelmediğinden emin olmak için, idrarını bir toplama kabına aldığını ve orada da kurtçukları görmesi üzerine hastaneye başvurduğunu ifade etmiştir.

Üriner sistem enfeksiyonu bulguları açısından sorgulanan hasta, ara ara idrarında yanma şikayeti olduğundan bahsetmiş, bunun dışında belirgin bir klinik semptom belirtmemiştir. Bulantı, kusma, kasık ağrısı, sık idrara çıkma ve hematüri şikayetleri olmayan hastanın, sistemik sorgulamasında herhangi bir semptom bulunmamıştır. Düşük sosyoekonomik düzey ve hijyen eksikliği enfestasyon için en önemli risk faktörleri olduğundan hastanın sosyoekonomik düzeyi ve hijyen durumu sorgulanmıştır. Literatürde tıbbi alanda sosyoekonomik düzeyi belirlerken kullanılabilecek standart, ortak bir ölçek oluşturulamadığı belirtilmekte olup, farklı çalışmalarda farklı ölçekler kullanılmıştır. Olguda literatürdeki Bacanlı (1997) ${ }^{12}$ tarafından düzenlenen sosyoekonomik düzey ölçeği ve Kut ve arkadaşları (2015)'nın ${ }^{13,14}$ önerdiği ölçek, araştırmanın amacına göre düzenlenip kullanılmıştır. Bu ölçeğe göre, çalışmamızdaki hastanın sosyoekonomik düzeyi yükseğe yakın orta düzeyde görülmektedir. Hijyen durumu ile ilgili sorgulamada, hasta tuvalet ve banyo temizliğini haftada iki kez dezenfaktanlarla yaptığını, tuvalet kağıdı kullandığını ifade etmektedir. Hayvan teması olmayan hastanın; piknik alanı, kırsal alan gibi açık ortamlarda tuvalet yapma öyküsü bulunmamaktadır. Aynı evde yaşayan diğer bireylerde benzer şikayetler olmadığı belirtilmiştir. Özgeçmişinde özellik bulunmayan hastanın, vital bulguları ve sistemik muayene bulguları normaldir. Genitoüriner sistemde açık lezyon ya da yara gözlenmemiştir. Tam idrar tetkikinde bir pozitif lökosit saptanan hastanın idrar kültüründe üreme görülmemiştir.

Psychoda spp.'ye bağlı genitoüriner miyaz tanısı konulan hastaya, tedavi olarak üriner antiseptik başlanmış ayrıca hijyen ve hastalık ilişkisi ve korunma yolları hakkında bilgi verilmiştir. Hasta bilgilendirmesinde; miyaz için en büyük risk faktörünün kötü hijyenik ortamlar olduğu, kişinin ve çevrenin özellikle kullanılan tuvaletin temizliğinin önemli olduğu, tuvaletlerdeki çöp kutularının temiz ve kapaklı olması gerektiği, tuvalet ve banyoda sineklere karşı gerekli önlemlerin alınması gerektiği, açık alanlarda özellikle hayvan gübresi bulunan yerlerde tuvalet yapılmaması gerektiği vurgulanmıştır. Takipleri yapılan has- 
tanın, larva düşürme şikayeti bir hafta kadar devam etmiş, sonrasında hastanın idrarında larva görülmemiştir.

\section{TARTIŞMA}

Ürogenital miyaz, seyrek rastlanan bir miyaz türüdür. Tüm miyaz olgularında olduğu gibi ürogenital miyazda da öncelikle zayıf hijyen koşulları en önemli risk faktörü olarak belirtilmektedir. Genital bölgede açık yarası olanlarda, temizlik gereksinimlerini tam olarak karşılayamadıkları için çocuklarda ve yaşlılarda daha sık olduğu bilinmektedir. Genel hijyeni bozuk kişilerde, özellikle beraberinde genital bölge enfeksiyonu varsa, oluşan kötü koku nedeniyle sineklerin bu bölgeye yumurta ya da larvalarını bırakmak için daha istekli oldukları düşünülmektedir ${ }^{3,15}$. Ayrıca larvalar bakterilerle beslendiğinden, insan yaşam alanları içinde tuvaletler, barındırdıkları mikrobiyal ortam dolayısıyla, sinek larvaları için en uygun ortamlardır ${ }^{5}$.

Bu çalışmada sunulan hasta; şehir merkezinde yaşaması, hayvan teması olmaması, açık enfekte yarası ya da üretral kateteri bulunmaması, üriner akıntı ya da üriner enfeksiyonu olmaması, altta yatan kronik bir hastalığa sahip olmaması nedeniyle ürogenital miyaz epidemiyolojisi ile örtüşmemektedir. Türkiye'nin farklı bölgelerinden hijyeni kötü olan hastalara ait Psychoda spp.'nin sebep olduğu ürogenital miyaz olguları bildirilmiştir ${ }^{10,16,17}$. Literatürde daha az sayıda olmakla birlikte, çalışmamızdaki olguya benzer şekilde; altta yatan hastalığı olmayan ve hijyen durumu iyi görünen hastalarda da ürogenital miyaz olguları bulunmaktadır ${ }^{6,18}$. Ürogenital miyazlı hastalarda, klinik yakınma olarak idrar yaparken yanma, sık idrara çıkma, idrarda kan görülmesi, yan ağrısı, pelvik bölgede ağrı, bulantı, kusma gibi şikayetler görülmektedir. Nadiren de zor ve ağrılı idrar yapma, kramp şeklinde karın ağrısı gibi daha şiddetli klinik bulgular bildirilmiştir. Bu şikayetler; zaten altta yatan bir üriner enfeksiyon olması nedeniyle görülebileceği gibi larvanın ayrıca üriner sistemde bir takım yangısal reaksiyonlar oluşturmasından kaynaklı da olabilmektedir ${ }^{5,7}$.

Sonuç olarak, ülkemizdeki birçok bölge iklim şartları açısından Psychoda cinsi erişkin sineklerin yaşaması için uygundur. Özellikle tuvaletlerde yeterince hijyenik tedbirlerin alınmaması veya farklı yerlerde kirli tuvalet kullanmak zorunda kalınması, daha az riskli kişilerde de enfestasyona sebep olabilmektedir. Tedavisi ve takibi yapılmayan hastalarda; tuvaletlerinde sineklere karşı gerekli önlem alınmaması, hijyene önem verilmemesi halinde; larvaların sayıca artabileceği, reenfestasyonların görülebileceği, mevcut enfestasyonun kronikleşip daha ciddi klinik bulgulara yol açabileceği ihtimali de göz önünde bulundurulmalı ve hastalar bu konuda uyarılmalıdır. Böyle olgularda hem gerekli tedavi ve takip yapılmalı hem de hastaya enfestasyonla hijyen arasındaki ilişkiye dair eğitim verilmelidir.

\section{ETIK KURUL ONAYI}

Bu çalışma, Necmettin Erbakan Üniversitesi Meram Tıp Fakültesi İlaç ve Tıbbi Cihaz Dışı Araştırmalar Etik Kurul onayı ile gerçekleştirildi (Tarih: 07.02.2020 ve Karar no: 2020/2314). 
Miyaz İçin Risk Faktörü Bulundurmayan Bir Kadın Hastada Psychoda spp.

Kaynaklı Ürogenital Miyaz Olgusu

\section{HASTA ONAMI}

Hastadan yazılı onam alındı.

\section{ÇIKAR ÇATIŞMASI}

Yazarlar bu makale ile ilgili herhangi bir çıkar çatışması bildirmemişlerdir.

\section{KAYNAKLAR}

1. Kara M, Arslan MÖ. Kuzeydoğu Anadolu'da hayvanlarda ve insanlarda myiasis. Atatürk Üni Vet Bil Derg 2011; 6(3): 245-50.

2. Miman Ö, Saygı G. Artropodlar, pp: 282-6. In: Temel Tıbbi Parazitoloji. 2018, 1. Baskı. İstanbul Tıp Kitabevleri, İstanbul.

3. Singh A, Singh Z. Incidence of myiasis among humans- a review. Parasitol Res 2015; 114(9): 3183-99.

4. Dik B, Uslu U, Isık N. Myiasis in animals and human beings in Turkey. Kafkas Univ Vet Fak Derg 2012; 18(1): 37-42.

5. Rasti S, Dehghani R, Khaledi HN, Takhtfiroozeh SM, Chimehi E. Uncommon human urinary tract myiasis due to Psychoda spp. larvae, Kashan, Iran: a case report. Iran J Parasitol 2016; 11(3): 417-21.

6. Yenice MG, Demir T, Babür C, Nalbantoğlu S, Kılıç S. Psychoda albipennis'in (Diphtera: Nematocera) neden olduğu ürogenital myiasis olgusu. Mikrobiyol Bul 2011; 45(3): 558-64.

7. Shimpi R, Patel D, Raval K. Human urinary myiasis by Psychoda albipennis: a case report and review of literature. Urol Case Rep 2018; 21: 122-3.

8. Yones DA, Bakir HY, Hameed DA. Human urogenital myiasis caused by Psychoda species larvae: report of five cases and morphological studies. J Adv Parasitol 2014; 1(2): 12-20.

9. Zumpt F. Myiasis in man and animals of the old world, pp: 267. A textbook for physicians, veterinarians and zoologists. 1965, Butterworths, London.

10. Sahin AR, Olker U, Nazik S, Guler S, Kirecci E. Urogenital myiasis caused by Psychoda albipennis. Turk Parazitol Derg 2018; 42(1): 93-5.

11. Güven E, Kar S, Doğan N, Karaer Z. Bir kadında Psychoda albipennis'in neden olduğu ürogenital myiasis. Türk Parazitol Derg 2008; 32(2): 174-6.

12. Bacanlı H. Sosyal İlişkilerde Benlik: Kendini Ayarlamanın Psikolojisi, 1997. İstanbul: MEB Yayınları.

13. Kut A, Salgür F. Sağlık alanında sosyoekonomik seviye belirleme: Medikal araştırmalarda doğru uyguluyor muyuz? Türk Aile Hek Derg 2015; 19(1): 4-13.

14. Geçkil AÜ. Tıbbi Araştırmalarda Sosyoekonomik Seviye Değerlendirme ve Gruplandırma Kriterlerinin Araştırılması. Tıpda Uzmanlık Tezi. Başkent Üniversitesi Tıp Fakültesi Aile Hekimliği Anabilim Dalı, 2015.

15. Saadawi WK, Shaibi T, Annajar BB. A human case of urogenital myiasis caused by Psychoda sp. larvae in Tripoli, Libya. Ann Parasitol 2017; 63(1): 69-71.

16. Karagüzel E, Kutlu O, Buruk K, Okatan AE, Özgür GK. Urogenital myiasis caused by Psychoda albipennis: a case report. J Urol Surg 2015; 2(4): 195-6.

17. Kaya S, Arslan M, Karaer Z, Köksal i. Psychoda albipennis'in neden olduğu ürogenital myiasis. Türk Parazitol Derg 2011; 35(3): 172-4.

18. Demir AD, Iraz M, İpek DNS. Bir çocukta Psychoda albipennis'in etken olduğu ürogenital myiasis. Türk Pediatri Arş 2015; 50(1): 65-8. 